\title{
EVENTOS EXTREMOS DE PRECIPITAÇÃO NO ESTADO DO PARANÁ
}

\author{
Carolyne B. Machado ${ }^{1,}$, Veronika S. Brand $^{1}$, Maurício N. Capucim ${ }^{1}$, Leila D. Martins ${ }^{1}$, Jorge A. \\ Martins $^{1}$ \\ ${ }^{1}$ Universidade Tecnológica Federal do Paraná - Câmpus Londrina \\ *carolyne.bmachado@gmail.com
}

\section{RESUMO}

Este estudo analisa o comportamento da precipitação no Estado do Paraná, através de métodos estatísticos para eventos extremos e ferramentas de SIG. Identificaram-se regiões mais vulneráveis a precipitações intensas, como o sudoeste do Estado, que apresentou chuvas intensas, recorrência de extremos anuais e tendência de aumento de extremos.

\begin{abstract}
This study analyzes the behavior of precipitation in the Parana State, trough of statistical methods to extreme events and GIS tools. It was identified more vulnerable areas to intense rainfall, as southwest of the state, that presented intense rainfall, recurrence of annual extremes and trend of increasing extremes.
\end{abstract}

\section{INTRODUÇÃO}

As projeções para o clima e identificação dos eventos extremos auxilia a sociedade em seu planejamento, adequação do setor hidroelétrico, etc., principalmente por sua dificuldade em considerar a variabilidade dos sistemas atmosféricos, baseando-se apenas em seu estado médio (VICENTE, 2004).

Muitos estudos vem projetando o aumento da intensidade de precipitação para o fim do século, no Sul do Brasil através de modelos globais. Como Torres e Marengo (2012), 0\% a 15\%; Tebaldi et. al. (2006) 0.25 a 1 ( $\mathrm{mm} /$ dia chuvoso). Além disso, muitos autores observaram que os modelos globais subestimam a precipitação no Estado do Paraná, como relatado por Solman et al. (2007) e Torres e Marengo (2012). Solman et al. (2007) ainda afirma que os modelos globais tem resoluções insuficientes para descrever os padrões de chuva em escala regional. 
O presente trabalho teve como objetivo caracterizar os eventos extremos do Estado do Paraná, identificando sua distribuição espacial e as tendências anuais dos índices de chuva e estiagem, fornecendo base para estudos posteriores.

\section{MATERIAIS E MÉTODOS}

Os dados de precipitação utilizados neste trabalho foram fornecidos pelo Instituto de Águas do Paraná. Foram consideradas 474 estações pluviométricas de 1079, por possuírem mais de 30 anos consecutivos de medição.

As análises estatísticas foram feitas de modo a identificar a frequência e intensidade de precipitações que podem causar desastres naturais. Teve-se base na Teoria dos Valores Extremos, estudada por Fisher e Tippet, que define a distribuição generalizada de valores extremos, atribuindo 3 tipos de funções. A função utilizada foi a de Gumbel (tipo I), que de acordo com Reboita (2005) é a que melhor se ajusta aos máximos das variáveis climatológicas. Os índices calculados anualmente estão descritos na Tabela 1.

Tabela 1: Índices de chuva calculados.

\begin{tabular}{|c|c|c|}
\hline Nome & Definição & Un. \\
\hline Precipitação anual & $\begin{array}{l}\text { Média do acúmulo de precipitação } \\
\text { anual. }\end{array}$ & $\begin{array}{l}\mathrm{m} \\
\mathrm{m}\end{array}$ \\
\hline & $\begin{array}{llll}\text { Parâmetro de locação } & \text { da }\end{array}$ & $\mathrm{m}$ \\
\hline $\mathbf{a}$ & Distribuição. & $\mathrm{m}$ \\
\hline $\begin{array}{l}\text { Tendência das } \\
\text { máximas anuais }\end{array}$ & $\begin{array}{l}\text { Inclinação da reta da regressão linear } \\
\text { das máximas precipitações anuais. }\end{array}$ & - \\
\hline T.R. $100 \mathrm{~mm}$ & $\begin{array}{l}\text { Tempo de retorno para ocorrer uma } \\
\text { máxima anual maior que } 100 \mathrm{~mm} \text {. }\end{array}$ & $\begin{array}{l}\text { ano } \\
\text { s }\end{array}$ \\
\hline$\%$ de dias chuvosos & $\begin{array}{l}\text { Dias com precipitação acima de } 1 \\
\text { mm sobre a os dias de medição. }\end{array}$ & $\%$ \\
\hline Parâmetro $\mu$ estiagem & $\begin{array}{llll}\text { Parâmetro de locação da } & \text { da } \\
\text { Distribuição. } & & \end{array}$ & dias \\
\hline $\begin{array}{l}\text { T. R. } 4 \text { semanas } \\
\text { estiagem }\end{array}$ & $\begin{array}{l}\text { Tempo de retorno para ocorrer um } \\
\text { período de estiagem anual maior que } \\
4 \text { semanas. }\end{array}$ & $\begin{array}{l}\text { ano } \\
\text { s }\end{array}$ \\
\hline
\end{tabular}




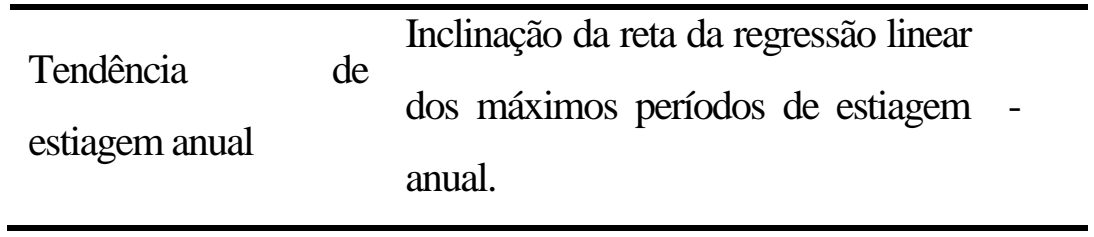

\section{RESULTADOS E DISCUSSÕES}

A Figura 1 apresenta os resultados obtidos com os índices de chuva no Estado do Paraná. Como se pode observar o litoral do Estado apresenta grande percentual de dias chuvosos 1-b e alta precipitação anual 1-a, correspondendo a uma região com chuvas bem distrbuídas, assim como a baixa recorrência de estiagem 1-h.

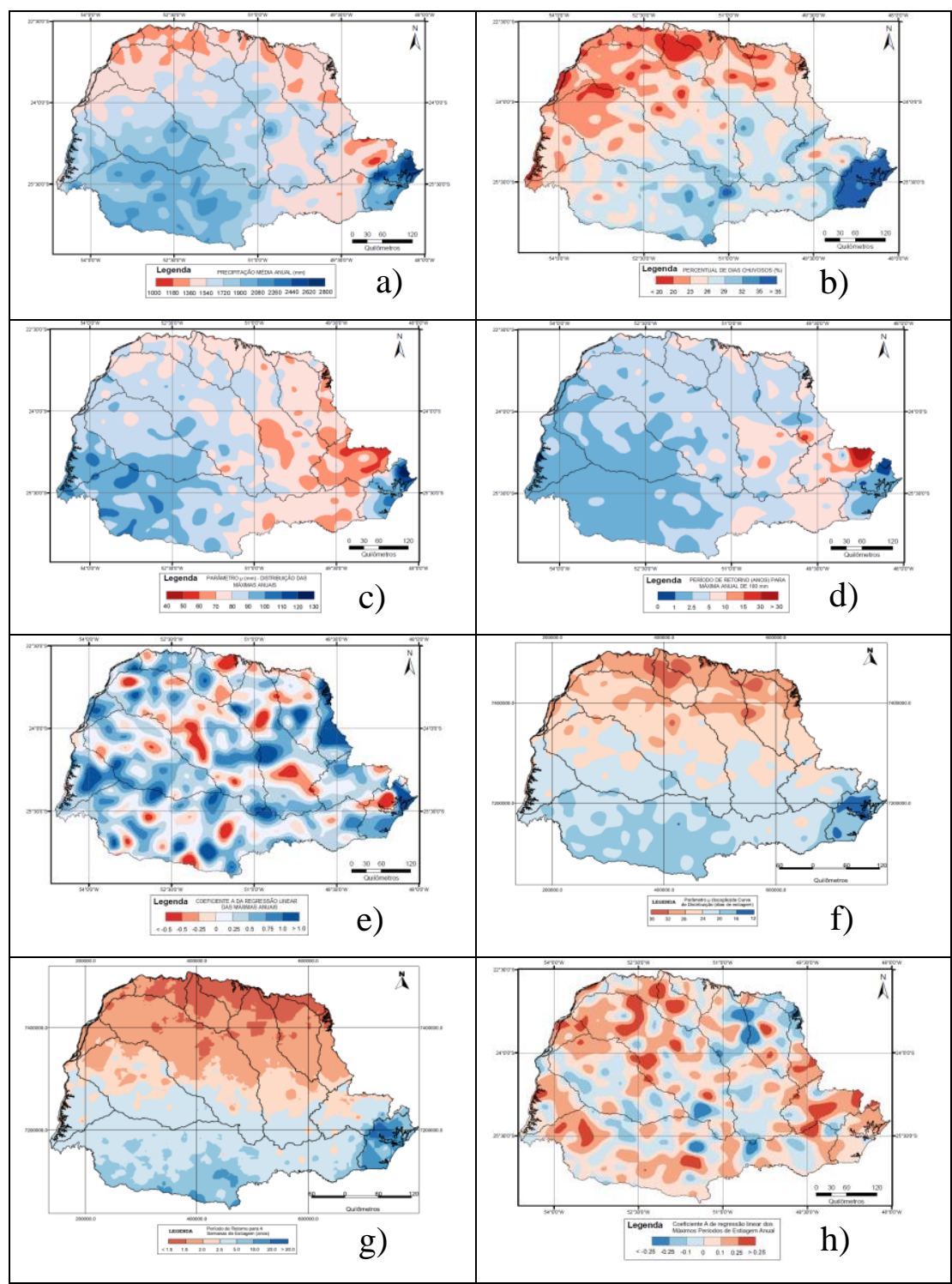

Figura 1: a) Precipitação anual, b) percentual de dias chuvosos, c) parâmetro $\mu$ de chuva, d) tempo de retorno para máxima de $100 \mathrm{~mm}$, e) tendência das máximas de chuva,f) parâmetro $\mu$ de estiagem, g) período de retorno para máximas estiagens de 4 semanas $e h$ ) tendência das máximas estiagens. 
Já o sudoeste do Estado possui altas precipitações 1-a, distribuídas em menos dias 1-b, correspondendo a chuvas intensas, confirmada pela recorrência de máximas acima de 100 mm 1-d. Além disso, essa região tem tendência de aumento de chuvas intensas, pelas regressões lineares de chuva (1-e) e estiagem (1-h) serem positivas.

O norte e noroeste do Estado possuem padrões de precipitação menos intensas 1-a, confirmado pela recorrência de grandes períodos de estiagem 1-g e por possuir poucos dias chuvosos 1-b. Essa região tem tendência de aumento de dias secos consecutivos 1-h, aferindo diversos problemas a sociedade, por exemplo sobre o setor hidroelétrico.

\section{CONCLUSÃO}

Com este trabalho, foi possível verificar a grande variabilidade espacial dos padrões de chuvas no Estado do Paraná, possuindo uma distribuição bastante hetereogênea. Além disso, verificou-se que regiões que já apresentam eventos extremos recorrentes, têm tendência de aumetar as chuvas intensas e também os períodos de estiagem. Além de regiões com pouca precipitação que tem tendência de aumentar os períodos de estiagem, como o norte do Estado.

\section{AGRADECIMENTOS}

Projeto financiado pelo CNPq, processo ${ }^{\circ}$ 555768/2010-4.

\section{BIBLIOGRAFIA}

REBOITA, M. S. Introdução à Estatística Aplicada à Climatologia - Parte II Distribuição de Probabilidades. Projeto PAE. São Paulo, 2005.

SOLMAN, S. A.; et al. Regional climate chane experiments over southern South America. I: present climate. Climate Dynamics, 2007.

TEBALDI, C.; et al. (2006) Going to the extremes An intercomparison of model-simulated historical and future changes in extreme events. Climatic Change.

TORRES, R. R.; MARENGO, J. A. (2012) Uncertainty assessments of climate change projections 
over South America. Theoretical and Applied Climatology.

VICENTE, A. K. Eventos Extremos de Precipitação na Região Metropolitana de Campinas. Universidade Estadual de Campinas. Instituto de Geociências. Campinas, 2004. 